Supporting material to:

\title{
"In-situ submicron organic aerosol characterization at a boreal forest research station during HUMPPA-COPEC 2010 using soft and hard ionization mass spectrometry"
}

Alexander L. Vogel, Mikko Äijälä, Ashley L. Corrigan, Heikki Junninen, Mikael Ehn, Tuukka Petäjä, Douglas R. Worsnop, Markku Kulmala, Lynn M. Russell, Jonathan Williams and Thorsten Hoffmann

\section{AMS Positive Matrix Factorization Spectra}

As it was described in the manuscript, the AMS factor analysis (Corrigan et al., 2013) resulted in a three factor solution (FPEAK=-0.4). Factor OOA-1 comprises two merged factors having high f44, since both factors had a very similar temporal behavior, uniform mass spectra and showed similar correlation to auxiliary measurements. The factor OOA-2 shows high $\mathrm{f} 43$ and was higher during the beginning of the campaign (see Figure 1).
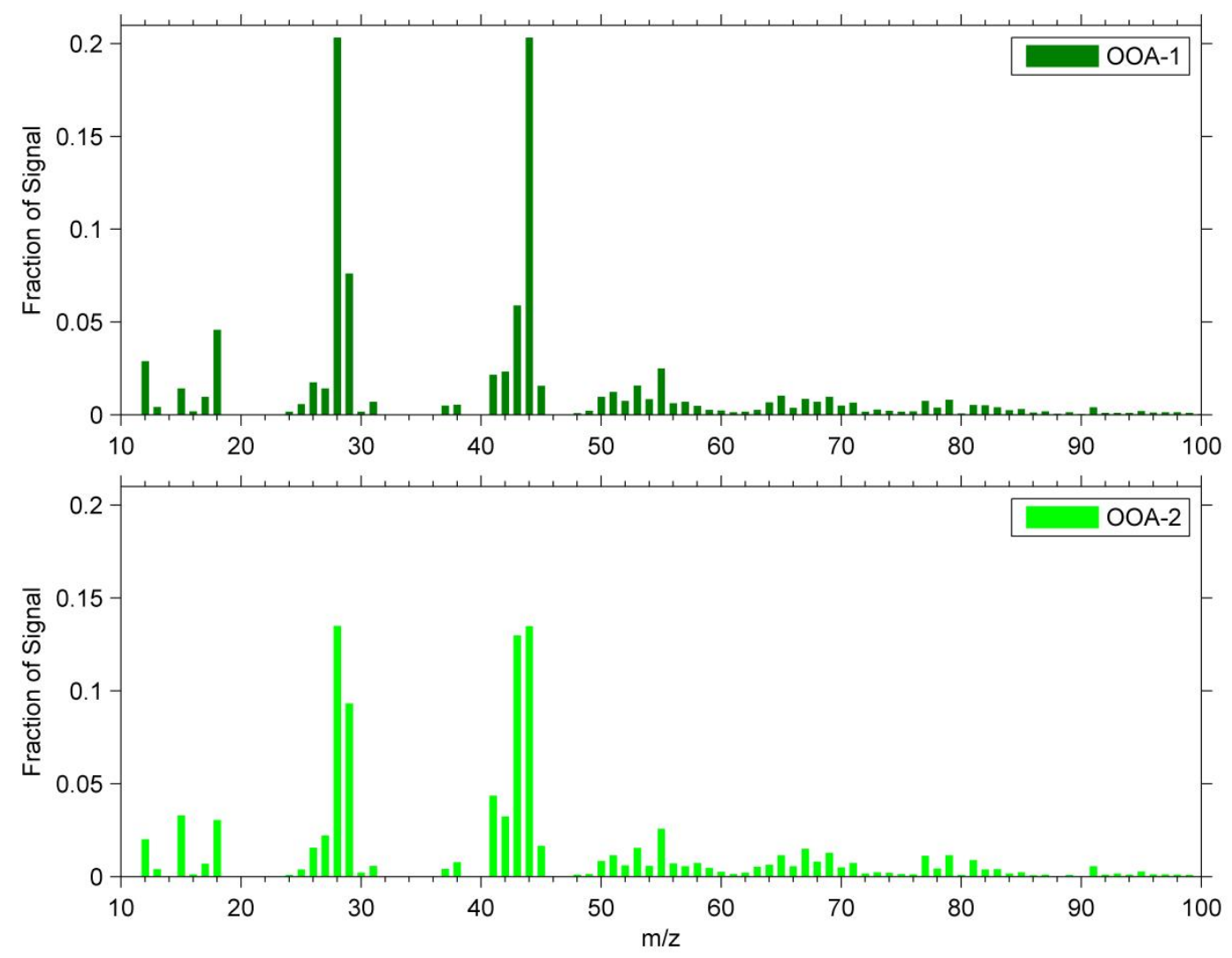

Figure S1 Mass spectra of AMS positive matrix factorization solution 


\section{Estimation of the average Oxidation States}

The average molecular oxidation state $\overline{O S}_{C}$ (Kroll, 2011) in the top panel of Fig. 4 was estimated for all signals in the range between $\mathrm{m} / z 163$ and $\mathrm{m} / z 237$ in the following practice: The average oxidation states of biogenic organic acids in this mass range which are described in literature (Tab. 2) were calculated after Eq. (S1) (Kroll et al., 2011):

$$
\overline{O S}_{C}=2 \mathrm{O} / \mathrm{C}-\mathrm{H} / \mathrm{C}
$$

For those acids, the ratio between particle phase (PP) and gas phase (GP) was calculated, based on the average of the measurements on 26 July 2010 12:00 - 15:00h (UTC+2) (the average mass spectra of this period are shown in Fig. 4, middle panel) and then plotted against $\overline{O S}_{C}$ (Fig. S2) with

$$
Q=P P / G P \text {. }
$$

A single term exponential fit resulted in $\mathrm{R}^{2}=0.55$, and was used to determine the $\overline{O S}_{C}$ of all unattributed $\mathrm{m} / \mathrm{z}$, ratios resulting in the red circles in the upper panel of Fig. 4. This approach does not account for the fact that multiple organic acids appear on one $\mathrm{m} / \mathrm{z}$ ratio, however, it nicely illustrates the repetitive character of an increasing oxidation state within the discussed mass range. This approach cannot be applied on a broader mass range, since the volatility is not only governed by the oxidation state but also by the molecular mass.

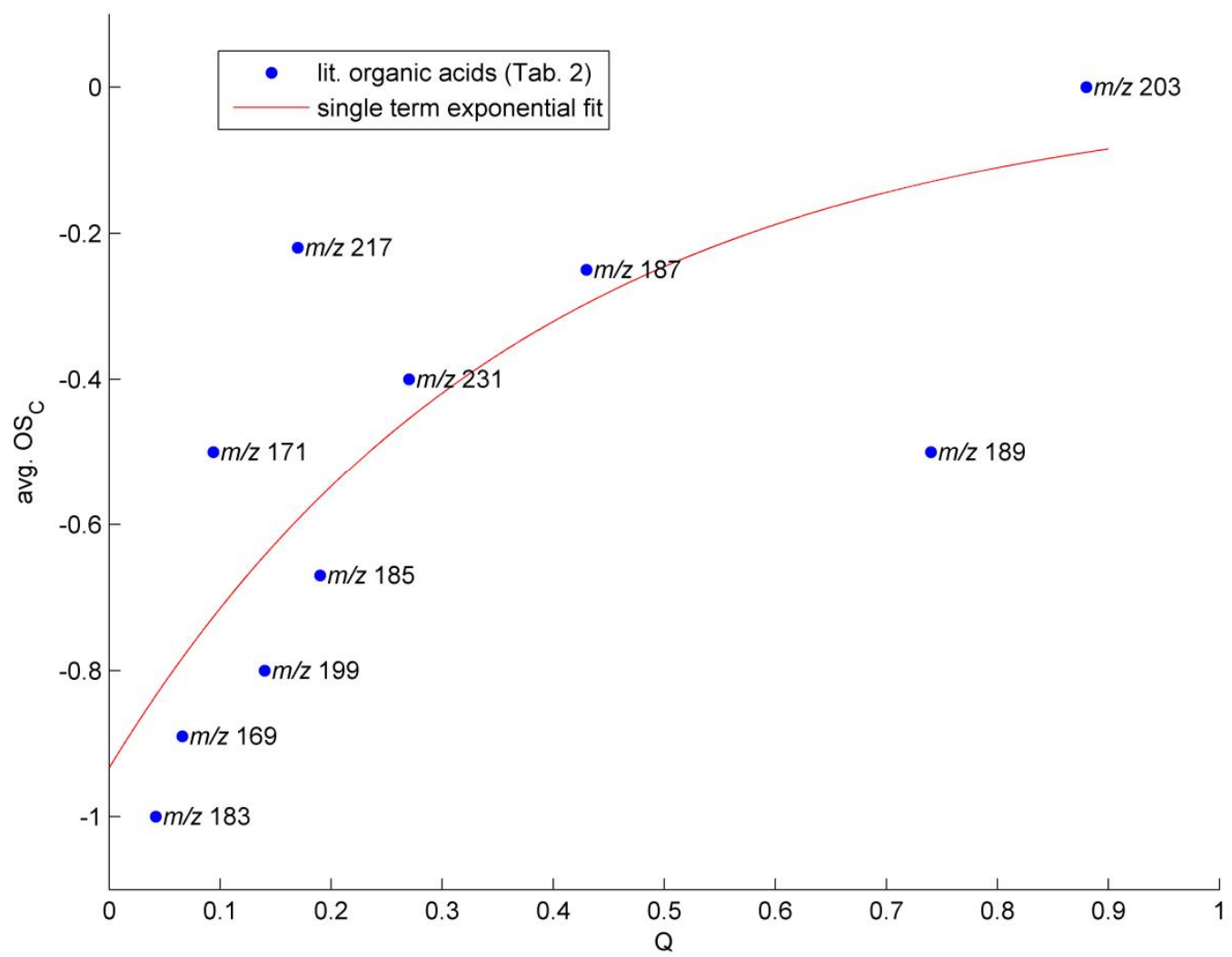




\section{Online $\mathrm{MS}^{2}$ spectra}

For completeness, all online-MS ${ }^{2}$ spectra, recorded during the HUMPPA-COPEC campaign on 22 July 2010 13:20-15:20h (UTC +2), are depicted in the following table.

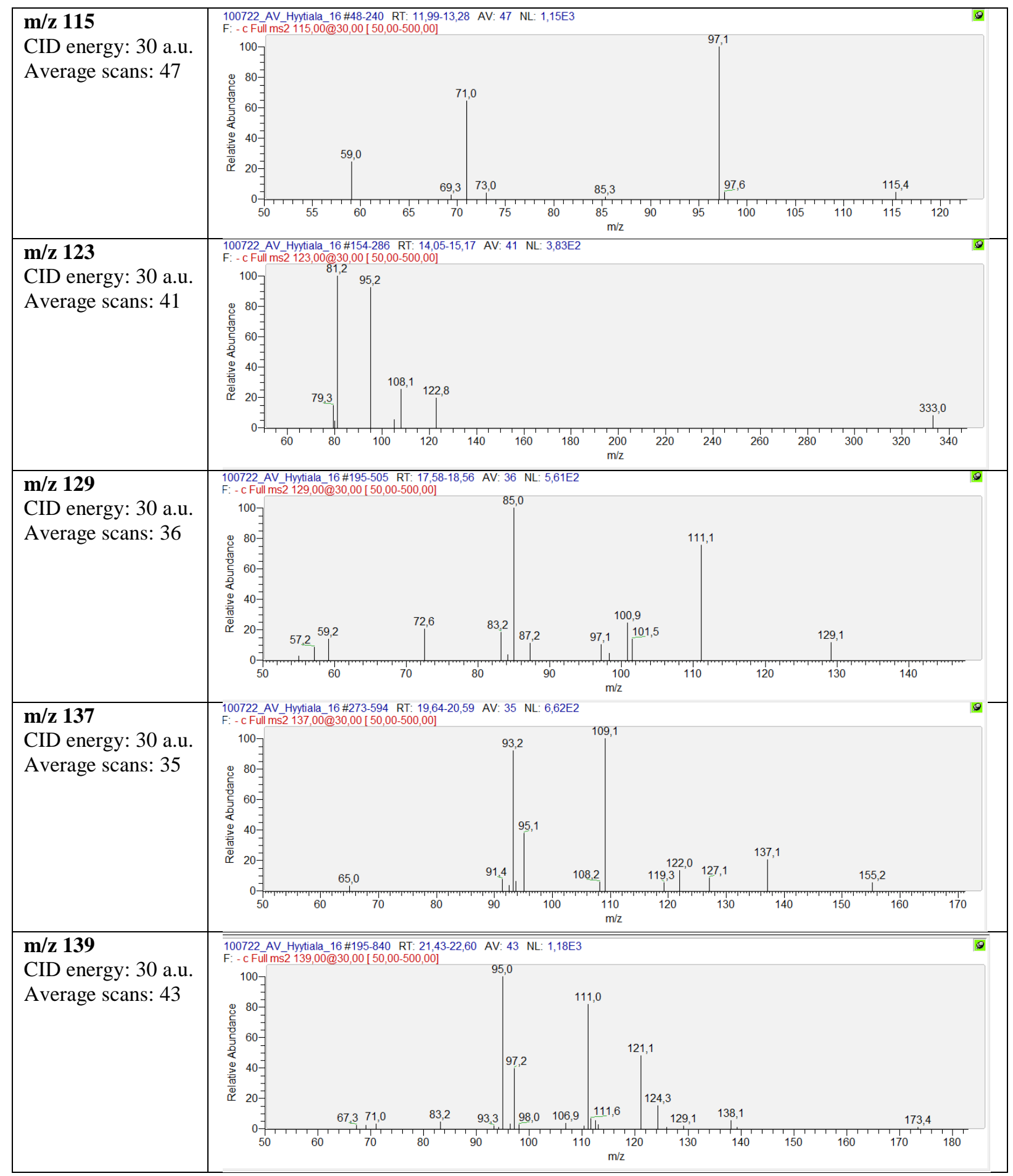




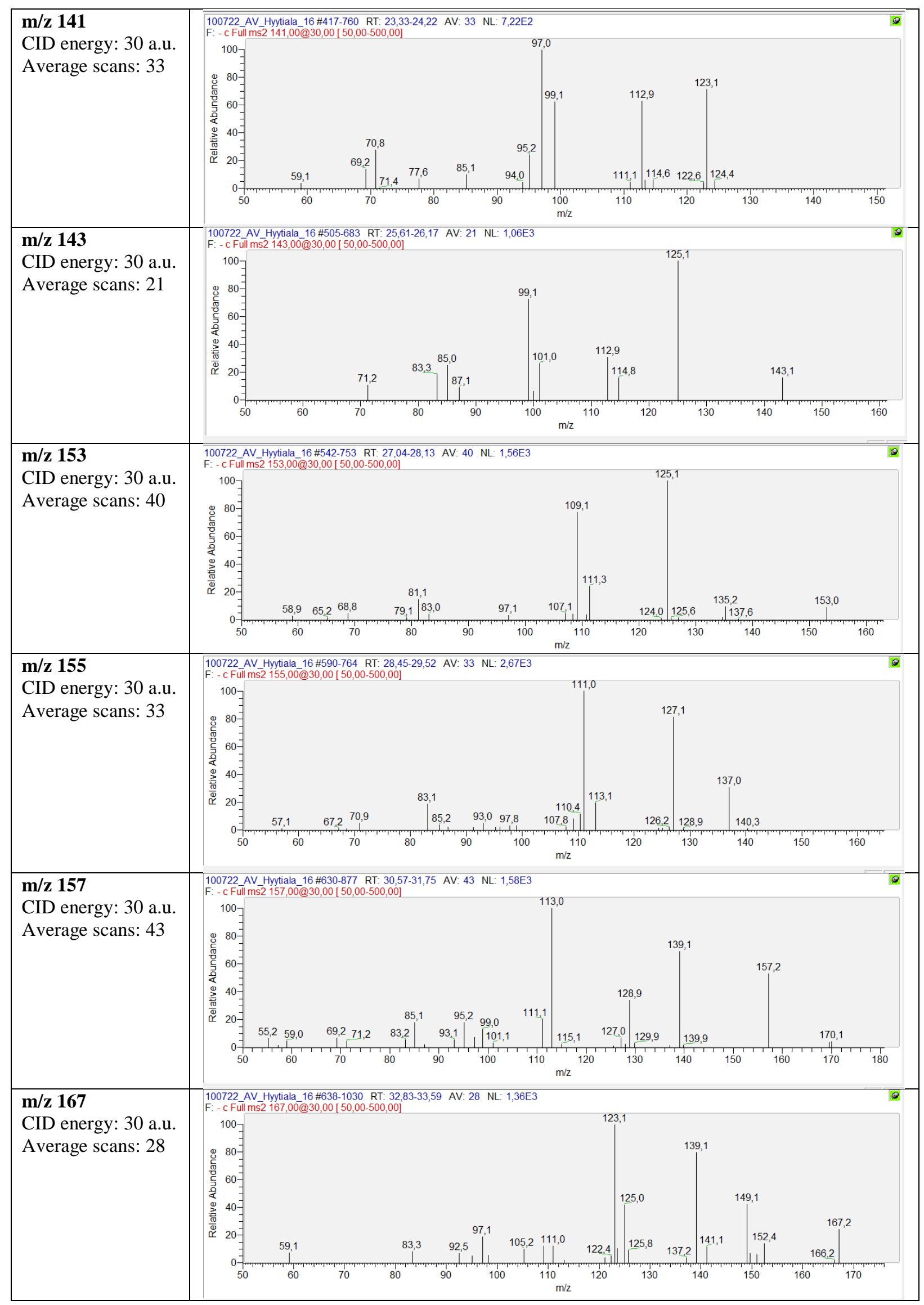




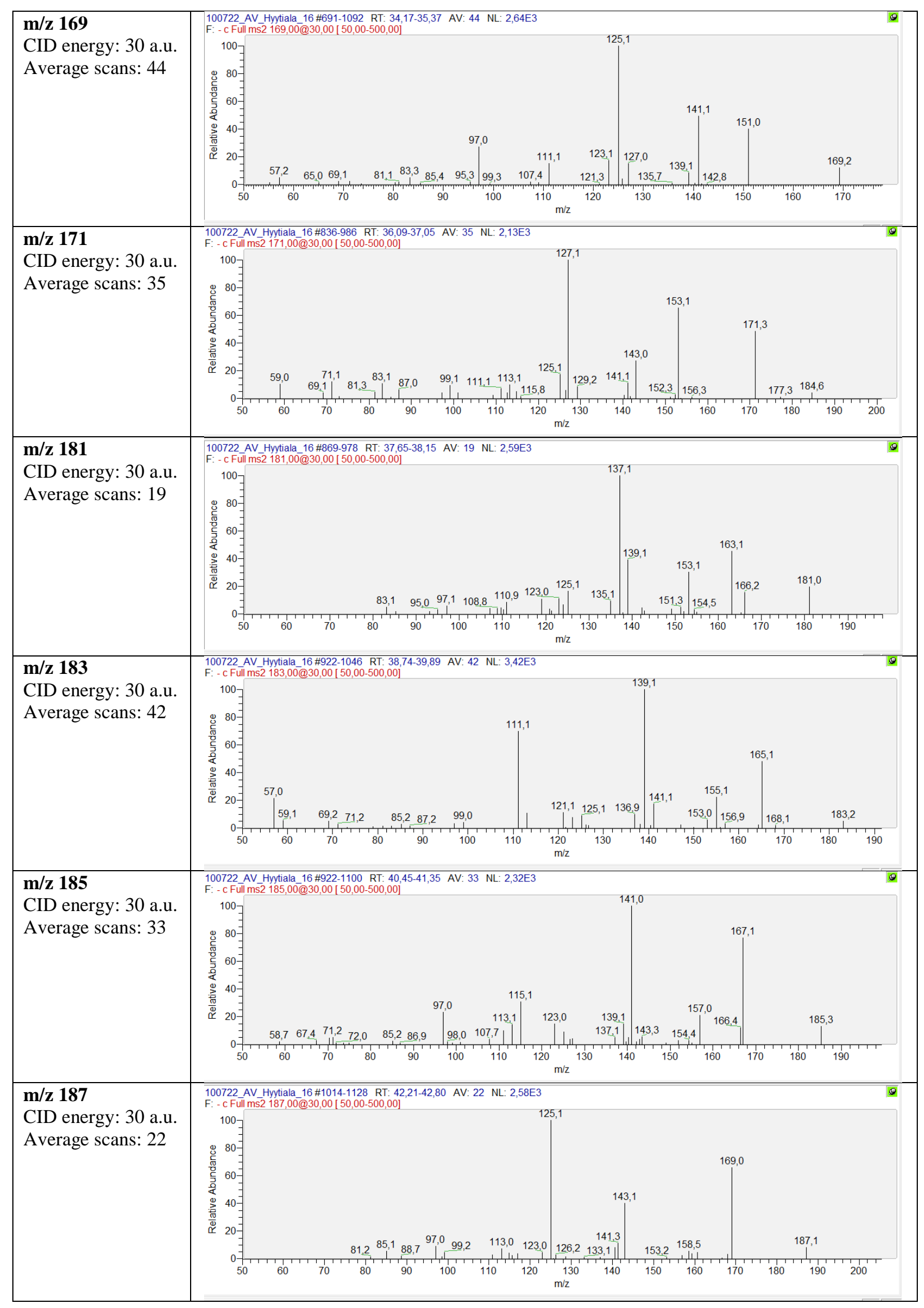




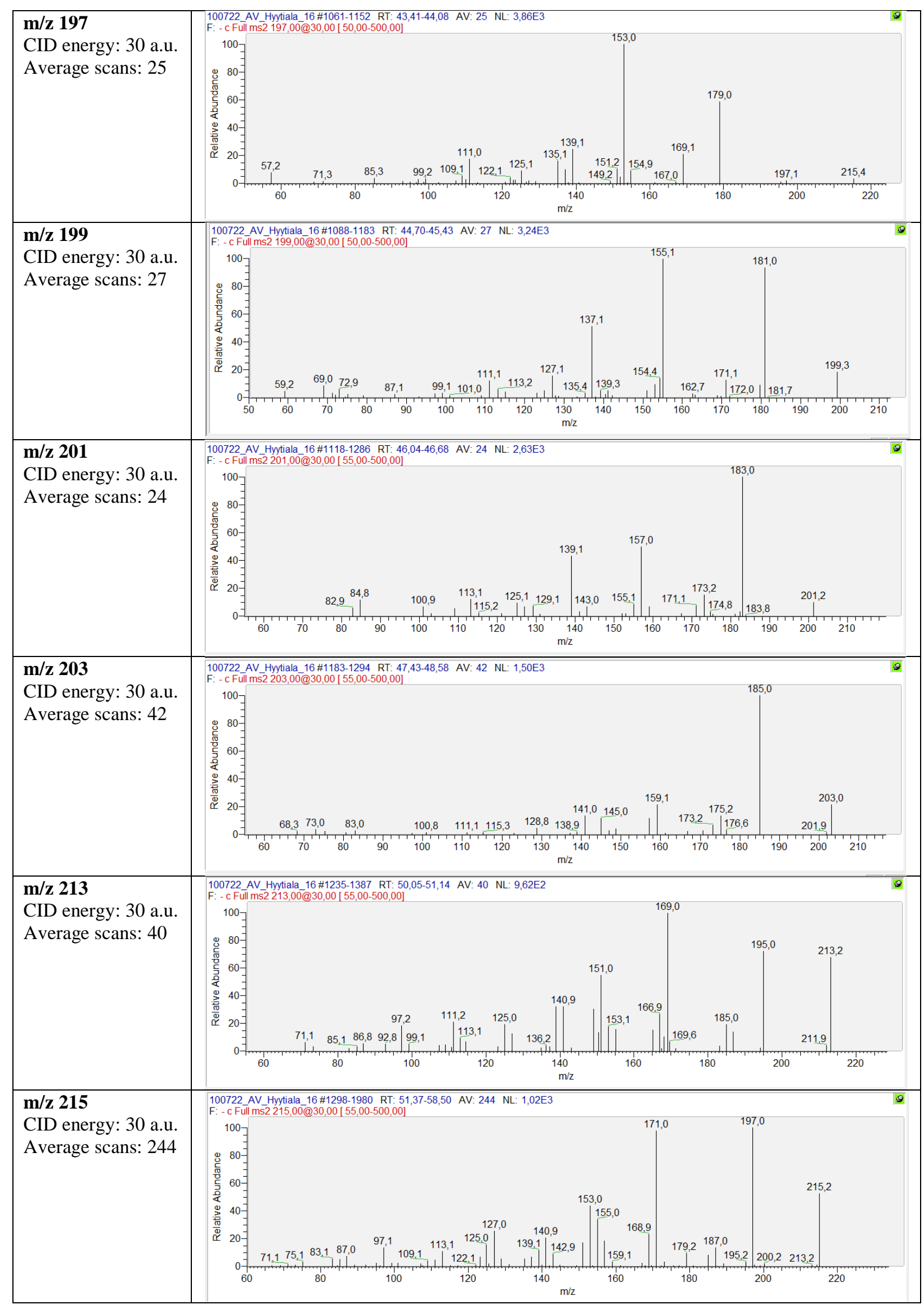




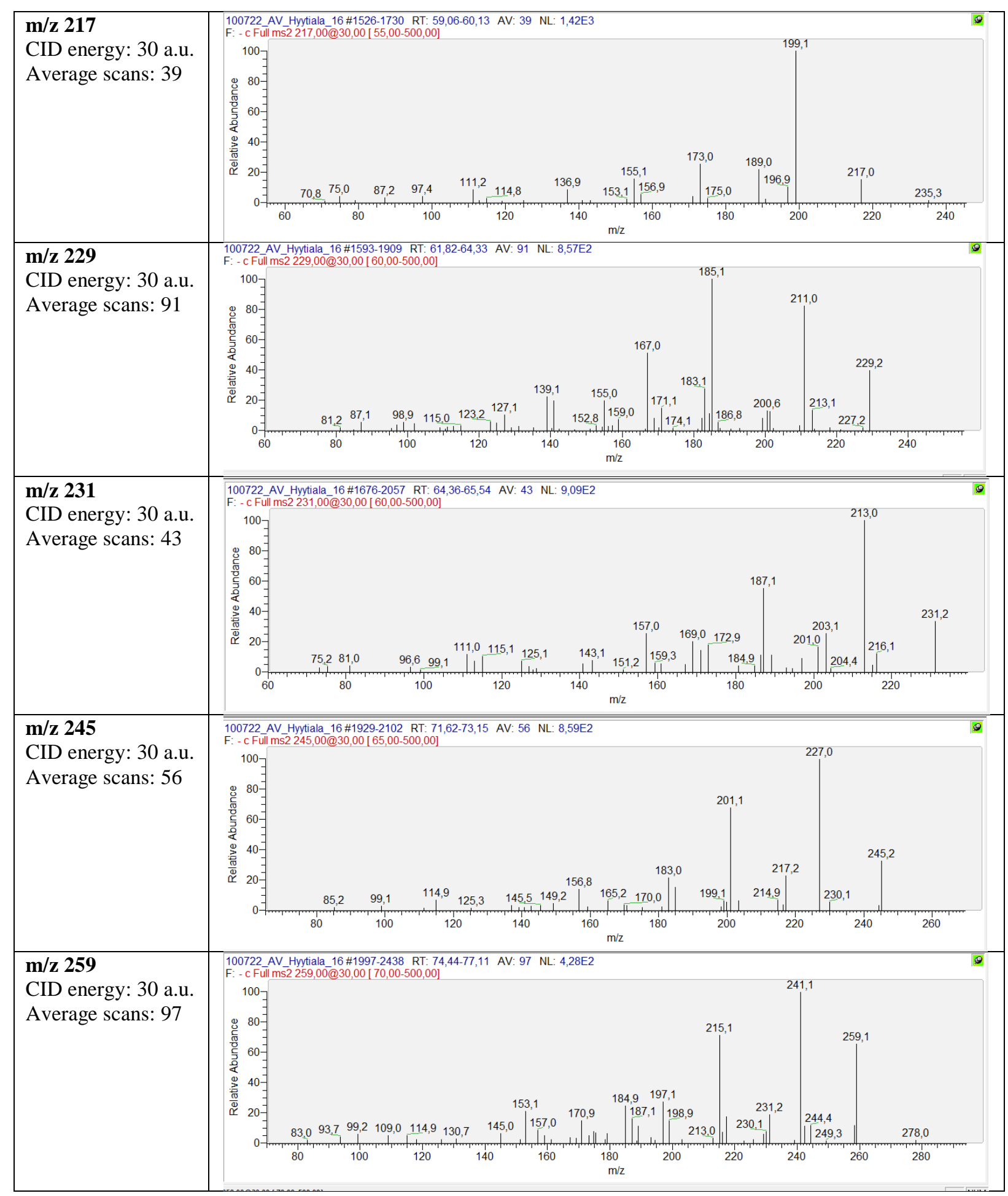




\section{Average molecular weight determination}

As it is mentioned in chapter 3.4, the determination of the average molecular weight can be seriously biased by the following phenomena: The determination can lead towards an underprediction of $\overline{M W}_{\text {om }}$ by multiply charged ions, fragmentation of the ions or by a higher ionization efficiency of low molecular weight compounds (Kiss et al., 2003; Graber and Rudich, 2006). $\overline{M W}_{\text {om }}$ can be biased towards an overprediction caused by a higher ionization efficiency of high molecular weight compounds, mass discrimination effects of small $\mathrm{m} / \mathrm{z}$ ratios or by cluster formation.

Stenson et al. (2002) showed by the use of an ultra-high mass resolution technique (ESI-FTICR-MS) that virtually all ions formed from humic and fulvic acid standards were singly charged. Testing several organic acids in the mass range of 120-200 Da in the laboratory supported these findings.

Concerning the issue of fragmentation it has to be distinguished between heat induced fragmentation and fragmentation due to the ionization process itself. Caldwell et al. (1989) described the thermal decomposition of small dicarboxylic acids (malonic acid and succinic acid) at temperatures as low as $120{ }^{\circ} \mathrm{C}$. In this work, the signal of ions $<\mathrm{m} / \mathrm{z} 150$ have low intensities compared to higher masses. Besides the fact that small dicarboxylic acids decompose very fast, those small weight acids are also affected by mass discrimination effects in the ion optics. These effects depend on the RF-voltage of the ion optics and can vary with different settings (e.g. the width of the spectrum). Aufmhoff et al. (2011) stated a mass discrimination effect of $\leq 2$ comparing $\mathrm{m} / \mathrm{z} 125$ to $\mathrm{m} / \mathrm{z} 160$ for an identical constructed ion trap. Since small weight dicarboxylic acids were described as the most abundant species in OA at a semiurban site (Khwaja, 1995), the thermal decomposition and mass discrimination effects of those small weight dicarboxylic acids might bias the picture of organic acids in the particulate phase substantially towards higher masses. Regarding the decomposition rate during the ionization process itself, it is commonly known that chemical ionization at atmospheric pressure is one of the techniques showing the smallest decomposition rates. Actually, the APCI technique shows less fragmentation than CI (which operates at a lower pressure regime), because the proton transfer in the ion/molecule reaction can leave an amount of internal energy in the product ion, which is sufficient for fragmentation of the product ion (Bartmess, 1989). At atmospheric pressure, the product ion can be stabilized rapidly by transferring the internal energy in a collision with a neutral molecule (Mitchum and Korfmacher, 1983).

Furthermore, the fragmentation of higher molecular weight compounds is different from small molecules. In short: Reemtsma and These (2003) showed that fragmentation of high molecular weight compounds is accompanied by hydrogen shifts, leading up to unity of the odd/even (or $M / M+1)$ distribution. The mass spectral pattern below $\mathrm{m} / z 200$ in Fig. 4 does show only a slight evidence for a biased odd/even distribution. E.g. the ratio of $\mathrm{m} / \mathrm{z} 187 \mathrm{tom} / \mathrm{z} 188$ is 0.14 . The $95 \%$ confidence interval ( $n=16$ scans) of this ratio ranges from $C_{8}(0.09)$ to $C_{14}(0.18)$ compounds. Since a $C_{14}$-carboxylic acid 
with the mass of $189 \mathrm{Da}$ is not reasonable, a possible explanation might be that hydrogen atoms shift due to fragmentation, or organic compounds including nitrogen. However, the upper limit value of 0.18 is still far away from unity, and thus fragmentation of higher molecular weight compounds, which is accompanied by hydrogen shifts, seems not to be a major issue.

Finally, the major uncertainty in predicting $\overline{M W}_{o m}$ is based on different ionization efficiencies of different organic compounds. This seems reasonable since different carboxylic acids do show a strong variation in gas-phase acidity, which results in compound dependent ionization efficiency. Unfortunately, the affinity between the negative ion $\mathrm{O}_{2}^{-}$and the analyte molecule cannot be assigned to certain chemical properties or to functional group contributions (Sekimoto et al., 2012) and further fundamental studies on the ionization process at atmospheric pressure are needed.

\section{Gas-to-particle partitioning}

As mentioned in the text, the gas-phase concentration might even be higher than observed, since the application of the water based concentrator might result in an underprediction of water soluble gasphase species due to diffusive losses in the saturator. These losses in the gas phase (app. $30 \%$ ) were not taken into account in calculating the partitioning between gas and particle phase.

Furthermore, the behavior of semi-volatile compounds in the condenser is highly uncertainnevertheless, for the calculation of the partitioning it was assumed that the semi-volatile acids in the gas phase condense onto the particle surface and thus get enriched as strong as the particle phase compounds while passing the virtual impactor (see Vogel et al. 2013 or Geller et al. 2005). This assumption leads to a lowermost estimate of the gas phase concentration of the semi-volatile compounds. However, future measurements of the gas-to-particle partitioning are needed in order to better understand the impact of the phase state of organic aerosols. 


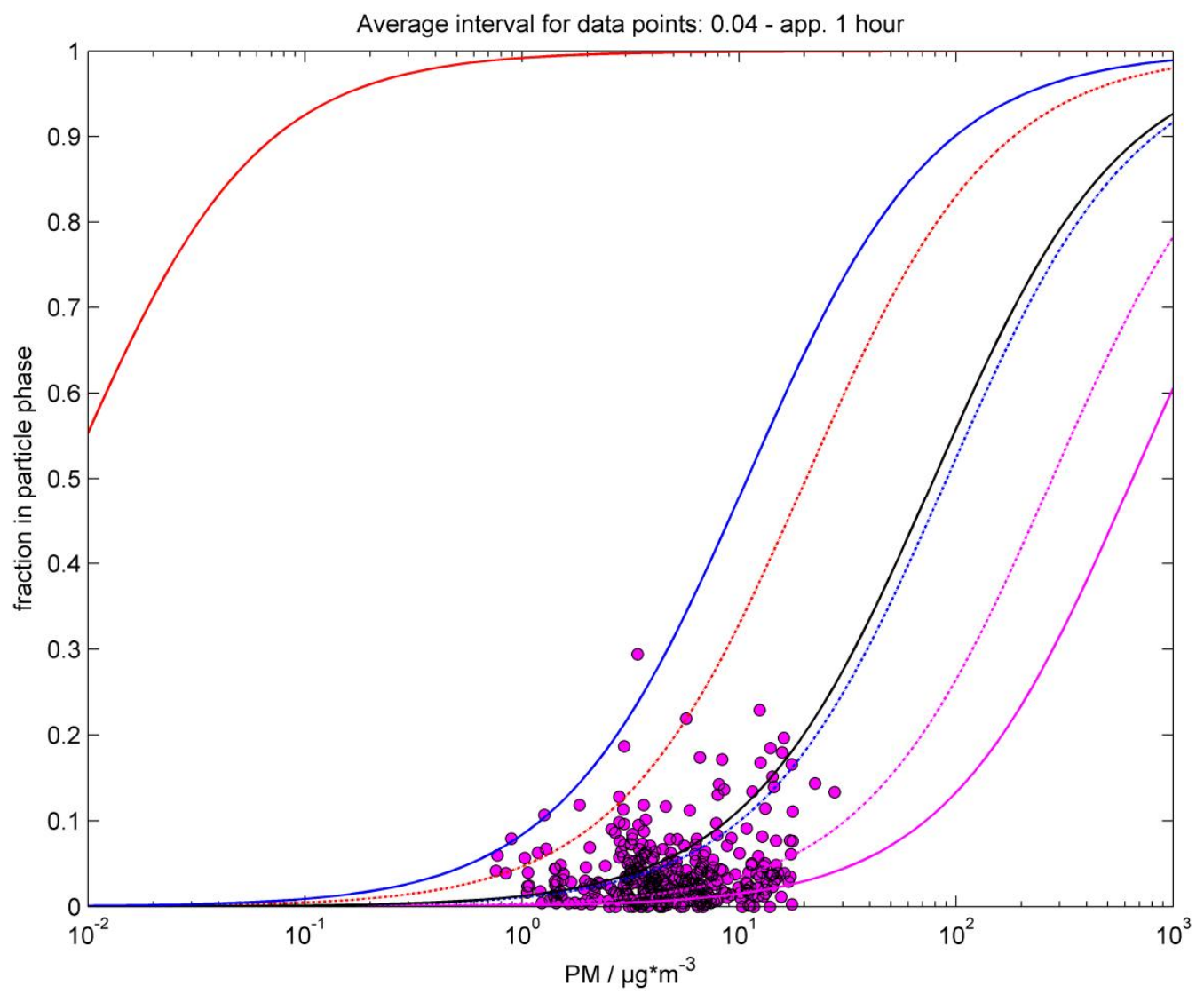

Figure S3a Gas-to-particle partitioning of $\mathrm{m} / \mathrm{z} 183$

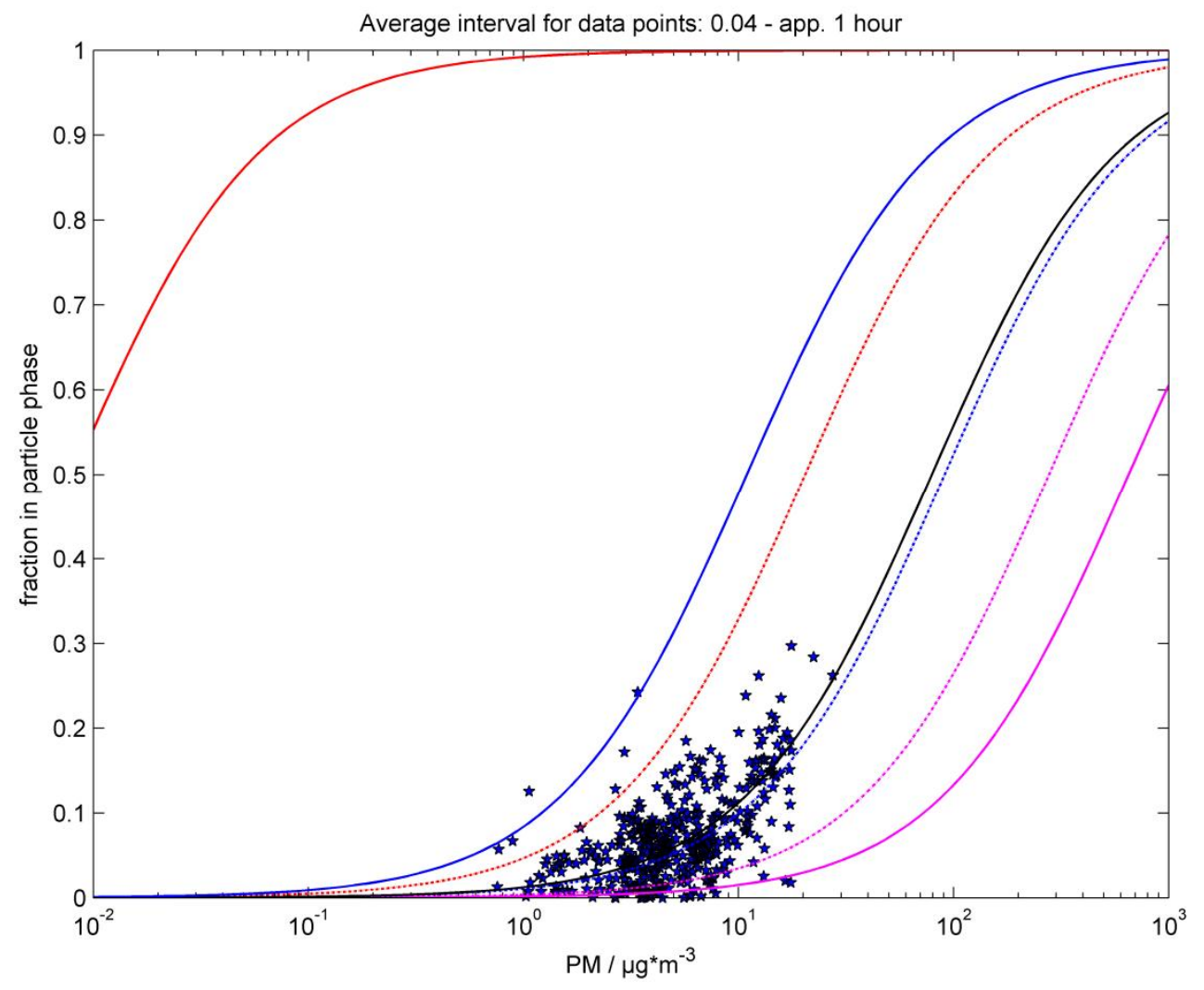

Figure S3b Gas-to-particle partitioning of $\mathrm{m} / \mathrm{z} 185$ 


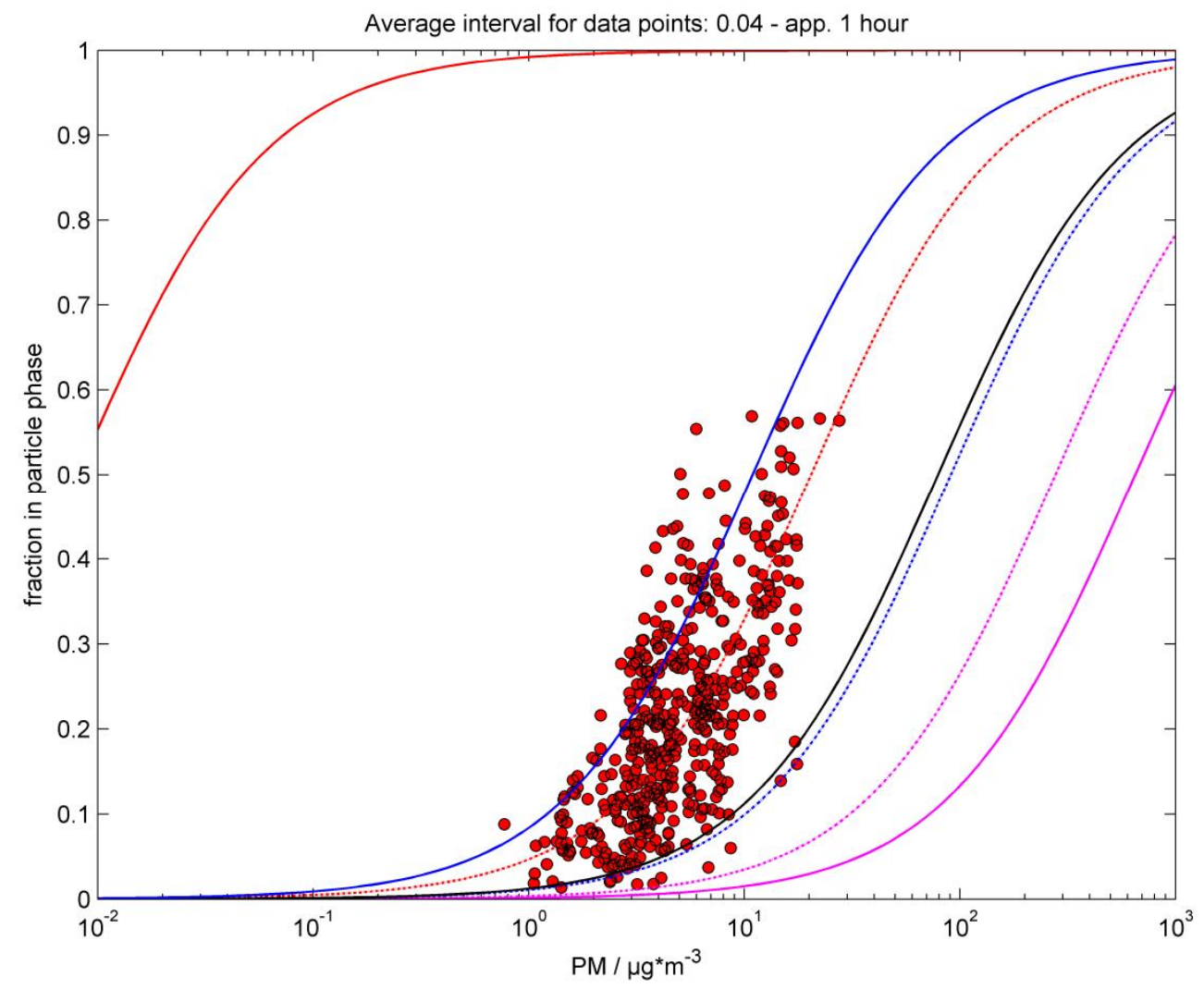

Figure S3c Gas-to-particle partitioning of m/ z 203 


\section{References}

Aufmhoff, H., Hanke, M., Uecker, J., Schlager, H., and Arnold, F.: An ion trap CIMS instrument for combined measurements of atmospheric $\mathrm{OH}$ and $\mathrm{H} 2 \mathrm{SO} 4$ : First test measurements above and inside the planetary boundary layer, International Journal of Mass Spectrometry, 308, doi:10.1016/j.ijms.2011.07.016, 2011.

Bartmess, J. E.: Gas-Phase Equilibrium Affinity Scales and Chemical Ionization Mass-Spectrometry, Mass Spectrometry Reviews, 8, doi:10.1002/mas.1280080502, 1989.

Caldwell, G., Renneboog, R., and Kebarle, P.: Gas phase acidities of aliphatic carboxylic acids, based on measurements of proton transfer equilibria, Canadian Journal of Chemistry-Revue Canadienne De Chimie, 67, doi:10.1139/v89-092, 1989.

Graber, E. R. and Rudich, Y.: Atmospheric HULIS: How humic-like are they? A comprehensive and critical review, Atmospheric Chemistry and Physics, 6, 729-753, 2006.

Khwaja, H. A.: Atmospheric concentrations of carboxylic acids and related compounds at a semiurban site, Atmospheric Environment, 29, doi:10.1016/1352-2310(94)00211-3, 1995.

Kroll, J. H., Donahue, N. M., Jimenez, J. L., Kessler, S. H., Canagaratna, M. R., Wilson, K. R., Altieri, K. E., Mazzoleni, L. R., Wozniak, A. S., Bluhm, H., Mysak, E. R., Smith, J. D., Kolb, C. E., and Worsnop, D. R.: Carbon oxidation state as a metric for describing the chemistry of atmospheric organic aerosol, Nature Chemistry, 3, 133-139, doi:10.1038/nchem.948, 2011.

Mitchum, R. K. and Korfmacher, W. A.: Atmospheric Pressure Ionization Mass Spectrometry, Analytical Chemistry, 55, 1983.

Reemtsma, T. and These, A.: On-line coupling of size exclusion chromatography with electrospray ionization-tandem mass spectrometry for the analysis of aquatic fulvic and humic acids, Analytical Chemistry, 75, doi:10.1021/ac0261294, 2003.

Sekimoto, K., Sakai, M., and Takayama, M.: Specific Interaction Between Negative Atmospheric Ions and Organic Compounds in Atmospheric Pressure Corona Discharge Ionization Mass Spectrometry, Journal of the American Society for Mass Spectrometry, 23, doi:10.1007/s13361012-0363-5, 2012.

Stenson, A. C., Landing, W. M., Marshall, A. G., and Cooper, W. T.: Ionization and fragmentation of humic substances in electrospray ionization Fourier transform-ion cyclotron resonance mass spectrometry, Analytical Chemistry, 74, doi:10.1021/ac020019f, 2002. 